\title{
Managing Safety in Small and Medium Enterprises
}

\author{
Stephen, legg; Olsen, Kirsten Bendix; Ian S., laird; Hasle, Peter \\ Published in: \\ Safety Science
}

DOI (link to publication from Publisher):

10.1016/j.ssci.2014.11.007

Publication date:

2015

\section{Document Version}

Accepted author manuscript, peer reviewed version

Link to publication from Aalborg University

Citation for published version (APA):

Stephen, L., Olsen, K. B., lan S., L., \& Hasle, P. (2015). Managing Safety in Small and Medium Enterprises. Safety Science, 71(Part C), 189-196. https://doi.org/10.1016/j.ssci.2014.11.007

\section{General rights}

Copyright and moral rights for the publications made accessible in the public portal are retained by the authors and/or other copyright owners and it is a condition of accessing publications that users recognise and abide by the legal requirements associated with these rights.

- Users may download and print one copy of any publication from the public portal for the purpose of private study or research.

- You may not further distribute the material or use it for any profit-making activity or commercial gain

- You may freely distribute the URL identifying the publication in the public portal -

\section{Take down policy}

If you believe that this document breaches copyright please contact us at vbn@aub.aau.dk providing details, and we will remove access to the work immediately and investigate your claim. 
Editorial

\title{
Managing safety in small and medium enterprises
}

\author{
S.J. Legg a,*, K.B. Olsen ${ }^{a}$, I.S. Laird ${ }^{a}$, P. Hasle ${ }^{b}$ \\ ${ }^{a}$ Centre for Ergonomics, Occupational Safety and Health, School of Public Health, College of Health, Massey University, Palmerston North, New Zealand \\ ${ }^{\mathrm{b}}$ Centre for Industrial Production, Department of Business and Management, Aalborg University, Copenhagen, Denmark
}

\section{A R T I C L E I N F O}

Keywords:

Small businesses

Occupational health and safety

Work environment

\begin{abstract}
A B S T R A C T
This paper presents a conceptual model for increasing acceptable working environments for SMEs. It also acts as an editorial for the special issue of Safety Science on 'Managing safety in small and medium enterprises (SMEs)'. It describes how seven of the ten papers in the special issue originate from an international conference in 2013 on Understanding Small Enterprises. It includes a commentary on the papers in the special issue as well as directing the reader to all of the current state-of-the-science sources known to the authors. The paper provides a background to previous research on safety in SMEs, showing how most current policy and legislation on occupational health and safety (OSH) and the work environment is based on large enterprises and that there is a relative paucity of research on OSH in SMEs. In a summary of current knowledge, it is argued that modern OHS legislation and interventions to help improve work environments need to increasingly take account of the specific characteristics of SMEs. The conceptual model for increasing acceptable working environments for SMEs takes its onset in a legislative standard that is built into intervention programmes and includes three instrument pillars: inspection to enhance compliance, recognition of the standard by the stakeholders in the industry sector and dissemination of information to small enterprises.
\end{abstract}

(c) 2014 Published by Elsevier Ltd.

\section{Introduction}

This special issue of Safety Science focuses on 'Managing safety in small and medium enterprises (SMEs)'. This paper, which also acts as an editorial, describes the origins of the special issue and provides a background and summary of current knowledge. It also includes a commentary on the papers in the special issue and an outline of key additional sources of information on 'Managing Safety in SMEs'.

\section{Origins of this special issue}

The special issue is underpinned by an ergonomics/human factors approach (www.iea.cc) that aims to simultaneously enhance both the work environment for people within SMEs and the business performance of SMEs. These dual concepts were originally captured in a conference on Understanding Small Enterprises held in Denmark in 2009 (USE2009), and again in the next conference in

* Corresponding author at: Centre for Ergonomics, Occupational Safety and Health, School of Public Health, College of Health, Massey University, Palmerston North, Private Bag 11222, New Zealand.

E-mail address: S.J.Legg@massey.ac.nz (S.J. Legg).
2013 (USE 2013) in New Zealand, organised by the co-guest editors (www.useconference.com). The different foci of the two USE conferences reflect a progression in the study of managing safety in SMEs. The first conference focused on 'understanding the issues (for practice)', whilst the second focused on 'putting understanding into action', with a theme of 'healthy work in a healthy business'. The specific topics addressed in the two conferences can be found on the conference web site: www.useconference.com. The progression is particularly reflected in the keynote topic titles, as well as in a wider perspective in the sessions, round table discussions and workshops. The last workshop at USE2013 ('What have we learnt from USE2013?') provided an up-to-date ad-hoc yet expert analysis of key current issues and is summarised, in brief, later in the present paper. These themes are reflected in this special issue.

Some of the papers in this special issue have their origins in presentations at USE2013. Others were independent submissions to the journal. As a group of papers, they reflect a mix of academic, research and practitioner contributions. Thus, this special issue reflects a growing interest in the relevance of an ergonomics/ human factors and an occupational health and safety (OHS) focus in SMEs. It also exemplifies the integration of academic, research and practitioner foci in addressing the management of safety in SMEs. 


\section{Background}

Most research, policy and legislation on OHS and the work environment has been, and still is, mainly based on large enterprises (usually defined as companies with more than 250 employees). There are many reasons for this, not least that they still employ a high proportion of employees - generally more than a third of the employees nationally (Targoutzidis et al., 2014) - and have the resources to influence, interact and contribute to policy development and research. Thus research on which legislation is built if it indeed is - is seldom based on research in SMEs (usually defined as businesses with less than 50 employees, but see below), since they do not have the resources (human, time and money) to contribute.

Performance-based regulation or reflexive regulation of OHS was first implemented in some western countries in the 1970s (Robens, 1972). This set out procedural requirements supporting self-regulation in which employers and workers had to formulate and implement health and safety policies and procedures to manage health and safety risks (Bluff et al., 2004; Quinlan et al., 2010; Walters et al., 2011). Since then, the industrial structure in most developed countries has changed dramatically. This has been characterised by larger organisations downsizing and/or outsourcing operations and services, implementing more flexible employment or contractual engagement of contractors - often small enterprises (Quinlan, 1999). This has contributed to an increase in numbers of SMEs. As a consequence of this change - and also on account of changes in technology, the working environment in both large and small enterprises has undergone massive transformations in the past few decades. In many jurisdictions these changes occurred relatively shortly after or alongside the transition to performancebased regulation. Thus, many of the settings upon which the transition was based - and hence current legislation in many countries is also based (such as large organizations standard employment contracts and high union density) have materially eroded (Mayhew and Quinlan, 1999). Nowadays, in most industrialised countries OHS is driven by Acts and associated legislation, regulations and Codes of Practice requiring enterprises to manage health and safety and create healthy and safe workplaces but do not describe how to do so. The consequence of the performance based (self-regulatory) legislation is that businesses are expected to manage risks that arise out of their business activity via internal risk management systems in order to create and maintain a safe and healthy work environment. This is particularly challenging for SMEs.

Over the last 30 years SMEs have received growing recognition as a valid form of economic activity in all parts of the world - with the potential to contribute to economic prosperity as well as social development. These contribute both to the overall economy in a number of measurable ways (employment and gross domestic product) as well as through providing services to the local and regional communities where they are based. In recent decades more attention has been directed at understanding the reasons for the existence of small firms - and understanding how they differ from large firms. SMEs are not simply infantile large firms they have a distinct and separate role to play in an economy.

Most modern economies are predominately composed of SMEs, which comprise a very high proportion of the total number of enterprises in many countries, employing a large percentage of the workforce. For example in the European Union, micro and small enterprises (1-50 employees) make up $98.7 \%$ of all enterprises and employ $50.2 \%$ of employees, whereas medium and large businesses (with more than 50 employees) make up only $1.3 \%$ of all enterprises but employ $49.8 \%$ of the employees (Targoutzidis et al., 2014). The same is true for many small nations. An example from the home country of three of the authors (New Zealand) is typical:
$97 \%$ of all businesses employ 20 or fewer people (i.e. SMEs) and account for $30 \%$ of all employees (Ministry of Business Innovation and Employment 2014), whilst 89\% employ five or fewer people and $68 \%$ have no employees (i.e. they are run by a single ownermanager or by one or more working proprietors). In this example, SMEs contribute to employment in a significant way, particularly in small towns or rural locations, where they account for $32 \%$ of total employment and have a share of about 33\% of total national sales and income (Legg et al., 2009). Thus the management of safety and the creation of healthy work systems in SMEs is an important issue for most nations to address, particularly when legislation and regulations are not specifically designed to fit the context of SMEs.

\section{Summary of current knowledge}

To date, research on OSH and the work environment in SMEs has been relatively limited. Much of it has been captured in the aforementioned USE conferences. For example, for a ten year period (2004-14) there were only 162 'hits'(articles) for a search on 16 October 2014 for the terms "SME OR "small business" OR "small enterprise" OR "small and medium size enterprise" OR SB" AND "Safety Science" on the database ScienceDirect, but after looking through the titles and abstracts only 35 of the articles were found to address issues specific to SMEs, and only 25 (listed in section 6 of the present paper) were published before this special issue. On average this is only 2.5 research articles per year. Similarly, the EBSCO hosted database Business Source Complete gave only 66 'hits' in a search limited to 2004 - 2014 for the terms ("health and safety" OR OSH OR OHS OR "work environment") AND ("small business" OR "small enterprise" OR SME).

Despite rather limited research to date, there is growing evidence that those working in SMEs are more frequently exposed to hazardous situations and suffer more work-related injuries and illnesses than those working in large businesses (Clifton, 2000; Micheli and Cagno, 2010; Sørensen et al., 2007; Targoutzidis et al., 2014). There is probably a high level of underreporting for small businesses. The European commission estimated that $82 \%$ of occupational injuries and $90 \%$ of fatal accidents happened in SMEs although less than $70 \%$ of the workforce was employed in SMEs (Targoutzidis et al., 2014). However the data available for analysing the influence of enterprise size on injuries and illnesses are poor, making 'analysis-by-size' difficult. The challenge of establishing the national injury/illness burden contributed by SMEs is even harder, because it is likely that there is more under reporting from smaller enterprises than larger ones. In addition, there is often a focus on injury and fatality, with less emphasis on ill-health and diseases, for which data for SMEs is commonly lacking (Legg et al., 2009).

There is, however, increased research interest in identifying the contribution to injuries and accidents from enterprises having different sizes - an acknowledgement of that size matters in OHS management (Micheli and Cagno, 2010; Sørensen et al., 2007). Micheli and Cagno (2010) argue that it is important not just to look at SMEs in relation to the nature of the accident burden but to divide SMEs into different size categories. They showed that there were differences between OHS performance of micro enterprises (less than 10 employees), small enterprises (between 11 and 50 employees) and medium enterprises (between 51 and 250 employees). The differences were between micro enterprises and the rest for average lost time days due to accidents, with the same pattern for frequency of severe accidents. Their findings emphasise the importance of identifying business size in OHS studies. Unfortunately this can be difficult because data on business size is often not specified, nor easily available. Thus, there is not only a need 
for a consistent and efficient way of gathering data for injury, illness and well-being in SMEs, but also for clear international agreement on definitions that logically divide SMEs into more distinct size-categories (Cunningham et al., 2014).

Most of the international literature on OSH and SMEs employing fewer than 20 staff suggests that the physical - but not necessarily the psychosocial work environment (Sørensen et al., 2007) is more hazardous than in large enterprises. Employees in SMEs with less than 20 staff are more often exposed to workplace hazards and suffer more work-related injuries and illnesses than those working in larger enterprises. These observations imply that some of the characteristics of SMEs make it more difficult for them to create and maintain a safe and healthy work environment and to manage safety (Hasle and Limborg, 2006; Mayhew and Peterson, 1999; Morse et al., 2004; Okun et al., 2001; Stevens, 1999; Targoutzidis et al., 2014; Walters, 2006). For example, Sørensen et al. (2007) suggest that the workplace, physical and chemical work environments in SMEs are particularly poor compared to larger organizations. Overall, the magnitude of exposure to OHS risks amongst the SME workforce is unknown, but is likely to be high and greater than that in larger enterprises.

\subsection{Characteristics of SMEs}

In general, small SMEs are characterised by management by the owner in a personalized (non-formal) manner, being independent, having a limited market share, high resource constraints, operating under extreme financial pressure (with high start-up costs and within tight profit margins) and having a high potential for failure (i.e. may have a short life-cycle). They have limited access to external sources of advice and support (hence are reliant on trusted relationships) and to business information/expertise. They also generally lack formal documentation (for OHS in particular) but the owner often has a high level of personal subject-specific technical knowledge and expertise. The management style suffers from lack of acumen, experience and training and tends to involve predominantly oral communication. Their lines of communication are shorter, their structure is simpler, commercial pressures are often felt more keenly and immediately, they are commonly less likely to have formalised management structures, an evolved or structured approach to OHS management, internal health and safety expertise or access to external sources of assistance (Baldock et al., 2006; Cagno et al., 2011; Hasle et al., 2009, 2012a; Hasle and Limborg, 2006; Laird et al., 2011).

SMEs are generally at a relative disadvantage due to economies of scale, are relatively isolated and geographically scattered. Small SMEs often employ family and/or friends, seasonal, casual or parttime non-unionized workers. They often suffer from skill shortages. Staff wages are often low. Jobs are less secure. The management characteristics that distinguish micro, small and medium enterprises are summarised in Table 1.

\subsection{Managing safety in SMEs}

Considering the characteristics of SMEs outlined above, it is hardly surprising that managing safety in SMEs - and in particular small SMEs - differs from its management in large organisations. Thus, relatively poor OHS management and outcomes in SMEs (in contrast to larger enterprises) may be attributed to characteristics that are typical of SMEs. These issues are further exacerbated in that SMEs are difficult to regulate due to their heterogeneous nature, geographical dispersion, lack of cohesive representation and relatively short-life spans (Dawson et al., 1988; Eakin et al., 2000; Lamm, 1999; Storey, 1994; Walters, 2001). Recent research (Cagno et al., 2011; Hasle et al., 2012b; Micheli and Cagno, 2010) suggests that relatively poor OHS management and outcomes in SMEs (in comparison to larger businesses) may indeed be attributed to their particular characteristics. This makes it more difficult for them to create and maintain a safe and healthy work environment and to manage safety and may explain why employees in SMEs are generally more frequently exposed to hazardous situations and suffer more work-related injuries and illnesses than those working in larger businesses.

It is impossible to separate safety management and practices from other (general management and operational) aspects of running a small business (Hasle et al., 2012b). The main characteristics of safety management systems in SMEs that have been identified are the use of oral rather than written communications, dependency on personal contacts - e.g. with suppliers for information (Hasle et al., 2012b; Olsen et al., 2010), limited knowledge of OHS Acts, Regulations and Codes of Practice (Olsen et al., 2010), a tendency to place OHS and injury responsibility with workers (Hasle et al., 2009), a belief that the agents (e.g. chemicals) being worked with are not dangerous (Hasle et al., 2009; Olsen et al., 2010), poor knowledge of health effects - in particular long term health effects (Olsen et al., 2010), hazard controls decided by custom and practice and not by risk assessment, and that economic survival is paramount (Hasle et al., 2012a). SME owners work very long hours and devote time to the most pressing issues. There is less time and energy for 'non-core' tasks of which managing safety is often perceived to be one. Key factors affecting safety management in SMEs have been identified as: low level of management and training skills, lack of resources, burden of compliance with regulations and codes, etc., poor relationship with regulatory agencies, cost of using OHS consultants, dependency on large businesses and, difficulties in implementing and understanding good safety practices.

Recent research (Hasle et al., 2012b) suggests that it is necessary to develop a better understanding of how small enterprise owner-managers gain their identity from their enterprise and how this, in itself, influences their safety management practices. Hasle et al. (2012b) suggest that because they get their identity from their enterprise, owner-managers try to avoid responsibility for injuries and illnesses. In preference they are inclined to transfer

Table 1

Management characteristics of micro, small and medium enterprises.

\begin{tabular}{|c|c|c|}
\hline Micro enterprises & Small enterprises & Medium enterprises \\
\hline Owner-manager & Both owner-managers and professionals & Often professional management \\
\hline $\begin{array}{l}\text { One management level, owner often works in } \\
\text { operation }\end{array}$ & $\begin{array}{l}\text { Two management levels, owner doesn't work in } \\
\text { operation }\end{array}$ & Several full time management levels \\
\hline Rarely growth and profit oriented & Sometimes growth and profit oriented & Stronger growth and profit orientation \\
\hline Very low division of work & Division of work with a few different professions & $\begin{array}{l}\text { Division of work with several professions and expert support } \\
\text { functions }\end{array}$ \\
\hline Low formalization - nothing in writing & Some formalization - systematic bookkeeping & $\begin{array}{l}\text { Formalization in terms of book-keeping, contracts, } \\
\text { certification }\end{array}$ \\
\hline
\end{tabular}


the 'responsibility' to the employees because they want to maintain good relations within their enterprise and this is often accepted by the employees through a social contract. They further suggest that owner-managers generally have a positive attitude towards creating a good work environment, but that it is a peripheral issue with potential for difficult ethical and economic consequences. In short, the relevance of employee participation in safety management practices in SMEs is not well understood (Masi et al., 2014). A better understanding of this aspect would be useful topic for future research.

\subsection{Safety intervention programmes for SMEs}

Although there are local, national and international agencies that promote the establishment and development of SMEs, adequate and effective OHS resources and support have not generally been provided. A recurring theme in the literature seems to be the identification of problems and challenges faced by employers, employees, enforcement agencies and researchers in relation to the development and implementation of OHS interventions. This is frustrating because, as shown above, it is already known that the particular characteristics of SMEs are implicated in preventing successful interventions particular to micro, small and medium sized SMEs. There is a general consensus that safety intervention models developed for larger companies are ineffective with SMEs and that difficulties contacting micro and smaller enterprises, their geographical dispersal and their short life spans, have all helped ensure that they have been left more or less to their own devices. However, attempts to address these issues have been made through the design and development of relatively simple, low cost solutions to control exposures, particularly in relation to chemical exposures (Walters, 2006).

A variety of models and preventive approaches have been developed at the international and national levels for use with small enterprises, the most common being the use of different types of checklists, implementation of OHS management systems and other preventive programmes (Legg et al., 2009; Walters, 2006). It has been suggested that the most successful methods appear to be tailored, action-oriented, low cost approaches, combining health and safety with other management goals, and based on trust, participation and dialogue (Hasle et al., 2012a; Hasle and Limborg, 2006; Masi et al., 2014). Other approaches include: training and educational interventions, engineering and industrial hygiene interventions, a combination of industrial hygiene, health promotion and behavioural interventions and enforcement. Interventions need to take the characteristics of the owner-manager into account (Laird et al., 2011; Masi et al., 2014). Thus, interventions also need to help the owner-manager maintain an identity as a good employer and therefore avoid criticism of the enterprise, contribute to employee satisfaction, set standards for an acceptable working environment that can be accepted by peers in the industry sector and increase legitimacy among industry sector stakeholders. Masi et al. (2014) identify the main drivers for this as: positive management and worker attitude towards health and safety, availability of guidelines, involvement of management in the production process, availability of economic resources, communication and, presence of associations and consultants.

In a keynote lecture by one of the authors - $\mathrm{PH}$ (unpublished) at the USE2013 conference (www.useconference.com) a conceptual model for increasing the acceptable working environment standards was presented (see Fig. 1). The model takes its onset in a legislative standard that is built into intervention programmes including three instrument pillars: inspection to enhance compliance, recognition of the standard by the stakeholders in the industry sector and dissemination of information to small enterprises. These three instruments create the mechanisms, within their particular contexts, that should encourage the owner-manager to pursue the standards: express societal legitimacy, signals of social acceptance and, provision of knowledge about the consequences of implementing or not implementing improvements.

Since SMEs are so numerous, geographically dispersed and diverse, one of the largest challenges is reaching SMEs with interventions. The model above can be extended to consider strategies for improving OHS or the working environment in small SMEs which should build on two principles: a high standard for acceptable working environment, and; effective support systems (see Fig. 2). The standards need to be described and communicated through regulation, including inspections that address specific health and safety issues, provide specific advice to solve the issues, be based on a dialogue with the owner-manager, and involve the social partners in the industry to secure legitimacy, implementability and responsibility for support of the standards. The support system needs to provide specific tools (not risk assessment tools) that provide concrete/specific solutions that are integrated into business strategies and should be based on a variety of different types of intermediaries that have personal contact to the ownermanagers and understand the business context.

Some of the most recent research has started to look more thoroughly at how different intermediaries can be used and what strategies should be applied to engage them (Olsen et al., 2010, 2012; Sinclair et al., 2013). SMEs are influenced by a range of stakeholders in both their internal and external environments. Key stake-

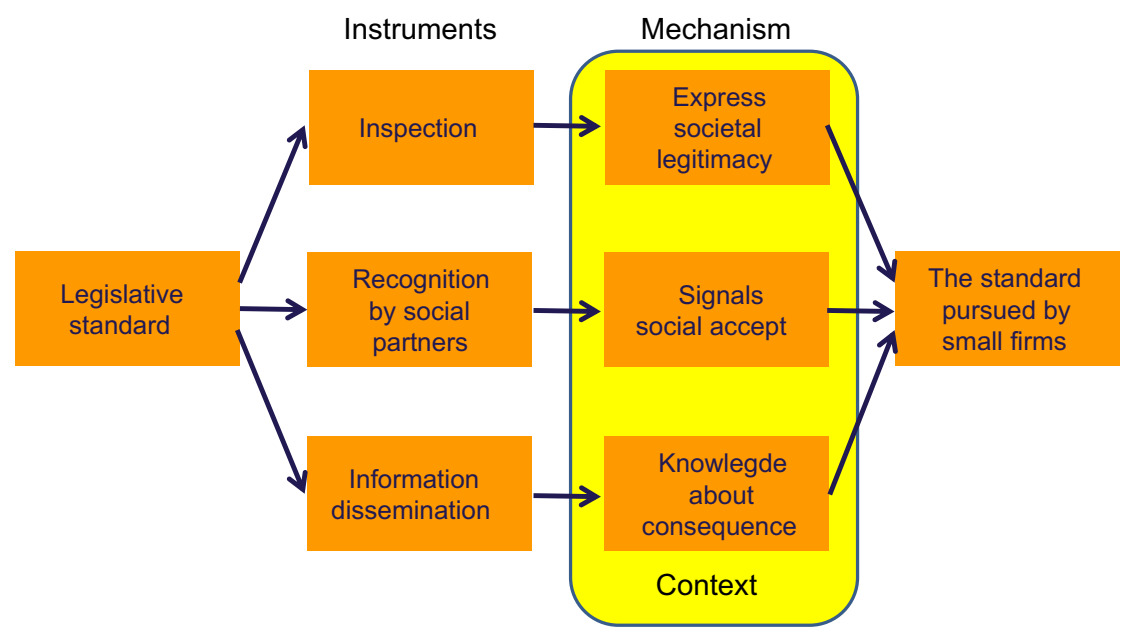

Fig. 1. Model for increasing the acceptable working environment standard in small SMEs. 

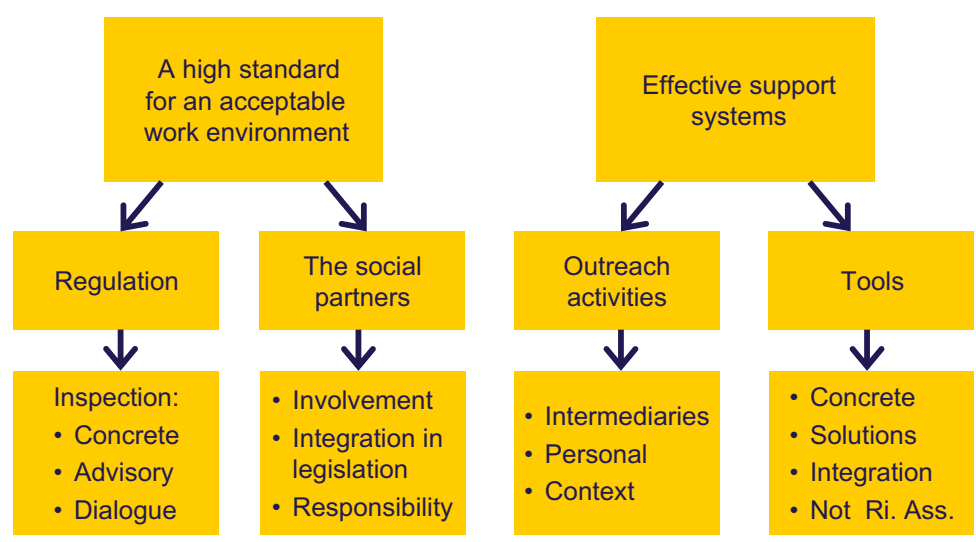

Fig. 2. Strategies for action to improve OHS in small SMEs.

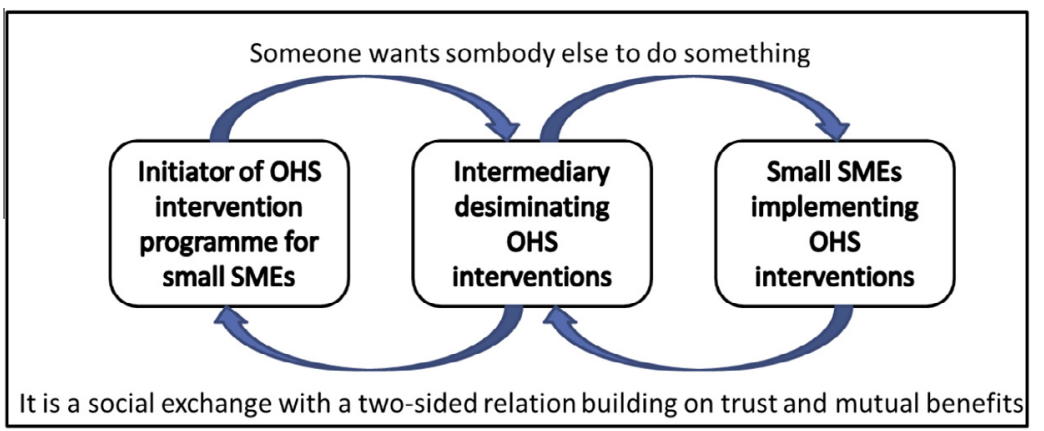

Fig. 3. Social relations in OHS intervention support systems.

holder groups that influence OHS management in small businesses include: customer, enforcement agencies, health and safety professionals, insurance companies, suppliers, trade associations, chambers of commerce and vocational training institutions. Different factors encourage the different types of small business stakeholders, as mentioned above, to address OHS improvements via intervention programmes. Thus, interventions not only need to address the characteristics of the SMEs but also of the intermediaries who deliver the interventions to the SMEs (see Fig. 3). These issues are specifically addressed in more detail in two of the papers in this special issue (Olsen and Hasle, 2015; Cunningham et al., 2015).

Sinclair et al. (2013) suggest that a better OHS intermediary could be characterised by: their commitment to align OHS activities with their business interests, already being engaged in delivering OHS products and services, seeking new ways of providing goods and services to small enterprises, being connected to small businesses through formal, informal or interpersonal relationships and, being innovative. It should be noted that these intermediaries include both OHS-focused intermediaries and non OHS-focused intermediaries.

\subsection{Ad hoc expert analysis of key current issues}

A final contribution to this paper's summary of current knowledge is provided via an ad hoc expert analysis of key current issues derived from the last workshop at the USE2013 conference. The workshop required conference participants (the 'experts') to form groups and answer the question: 'What have we learnt from the USE2013 conference?' This section summarises their responses.

The sessions at USE2013 on practical tools for SMEs concluded that there was a specific need to change focus from development of risk identification and assessment tools that merely identified the problems in SMEs, to development of more holistic tools that could identify how well-being could be improved in SMEs. These sessions also identified the need for evaluations to assess both health and economic cost benefit of the interventions. Practical tools should be based on participation and be implemented stepwise to secure transfer of knowledge and raise motivation.

Several sessions focused on specific sectors - fishing, agriculture and hospitality and tourism. The conclusions from these sessions were that there is still a need to identify the health and safety problems and the causes of these problems because the measures of health and safety outcomes in these sectors are still poor. The participants identified the need for national research and intervention initiatives that integrated OHS into design of machinery and other facilities and that made better use of consultants and other intermediaries with contacts to SMEs. Tools should be developed in partnership with branches and industries and should include integration of OHS in training of managers and workers. This should be discussed and developed within a network of international collaboration. A major issue for these sectors was considered to be the high prevalence of migrant workers. This was linked to a major concern for developing countries - the large size of the informal sector. There is also a need to find methods to identify and address these particular problems in these sectors.

The theme of the conference - 'from understanding to action' was addressed. The groups identified some key issues that need to be considered when designing, implementing and evaluating interventions for SMEs. A fundamental issue of particular concern was 'how to use the current knowledge' about intervention limitations, resources and constraints in SMEs, especially in relation to specific sectors. Two examples were: partnership between employers and a government agency (Sweden), and; partnership between a gov- 
ernment agency and universities which created a 'Centre for health management of workers supporting SMEs'. Interventions like these should involve participation of the social partners in the sectors. Additional identified needs were: to build on trusted change facilitators; participative involvement of workers in the creation of tools, and; creation of a link between good work and product quality and productivity. Another key issue was that successful government intervention programmes need to reach poor SME performers. Government commitment is essential and involves formal and informal intermediaries such as industry associations, networks and services (e.g. public health services) and local community groups (e.g. church communities). A relationship to these intermediaries needs to be developed with a give-and-take approach. Governments need to provide seed funding to develop collaboration within a targeted sector to develop networks and common rules and standards. Governments also need to enforce jointly developed standards to create engagement from owner managers.

Finally to conclude, suggestions for future research and action were to: maintain a focus on 'creating healthy lives in healthy businesses', encourage more decision makers and politicians to participate in research on OSH in SMEs, create an international network of researchers, legislators and politicians to address OSH SME issues internationally, extend the focus on applied practice addressing health leadership, practical tools, occupational health services, conduct more case studies of good practice, determine how to implement risk assessment, address psychosocial risk management, consider the role of occupational health/medical services and/or occupational physicians, and address the relation between corporate social responsibility and health and safety issues in the future management of safety of SMEs.

\section{Commentary on the papers in this special issue}

Twenty-four papers were submitted for consideration for this special issue. Fourteen papers were rejected, either immediately by the co-guest editors as unsuitable or after double blind peer review. Ten papers were accepted for publication. Of these, seven were based on presentations at the USE2013 conference and three were independent submissions.

The first two papers (Holizki et al., 2015; Holte et al., 2015) focus on the epidemiology of injury in relation to small businesses. Holizki et al. (2015) describe the patterns of underlying causes of work-related traumatic fatalities in comparison between small and larger companies in British Columbia. All traumatic fatality data from the Workers Compensation Board of British Columbia were used to determine underlying patterns of cause of fatalities in different industries and to assess differences between small and larger businesses. Fatality rates for small businesses were significantly higher than in larger businesses. Factors for which there were significant differences by employer size included fatalities within one month of employment, fatality rates in primary industries and transportation, vehicular incident fatality rates, and seat belt use. They conclude that prevention strategies are needed to address training and supervision of new workers in small businesses. Holte et al. (2015) similarly report on the differences in injury prevalence among apprentices in building and construction in Norway, according to company size.

The next two papers (Cunningham and Sinclair, 2015; Masi and Cagno, 2015) describe intervention models and consider barriers and enablers for their effective implementation in small businesses. Cunningham and Sinclair (2015) describe four case studies from the US on the application of a model for delivering occupational safety and health to smaller businesses. Masi and Cagno (2015) describe barriers to OSH interventions in SMEs. Their study is based on interviews with SME safety officers and gives an overview of the most frequent barriers to OSH interventions, as well as of the effect of the intervention process phase, of the firm's size and of the industry sector.

The next four papers (Ipsen et al., 2015; Kvorning et al., 2015; Olsen and Hasle, 2015; Ozmec et al., 2015) examine the effects of various national and organisational level interventions aimed at improving the work environment in SMEs in a range of industry sectors (agriculture, construction, auto-repair, software development, welding, surveying, manufacturing assembly line). The paper by Olsen et al. (2015) uses programme theory and realist analysis in a case study evaluation of a national insurance incentive programme (the New Zealand Workplace Safety Discount scheme) in the agriculture sector. They analyse the role of intermediaries in delivering an occupational health and safety programme designed for small businesses. The study highlights the importance of analysing the business interests of different types of intermediaries when deciding which intermediaries to involve in OHS schemes for small businesses, to optimise the intermediaries' active support and outreach to the targeted small businesses. The paper by Kvorning et al. (2015) also uses programme theory and realist analysis to examine a national level 'prevention package' programme (in Denmark). They show that the efficacy of the programme was very dependent on 'contextual factors', and that these should be taken into account when designing programme to help improve the work environment in SMEs. Ipsen et al. (2015) describe an organisational-level intervention (again in Denmark) and, like Masi and Cagno (2015), consider enabling and facilitating factors. Their findings are consistent with the above summary of current knowledge in that the dominant inhibiting factor in SMEs in their study was a strong focus on daily operations and a lack of time for the intervention. Ozmec et al. (2015) (also from Denmark) used a qualitative phenomenological case study approach to show that safety was rarely an explicit focus for SME employees, and that safety issues were rarely shared or communicated within the company. Their case illustrates that injury prevention approaches should take into account the limited impact of owner-managers on day-to-day practices.

The final two papers (Farina et al., 2015; Reinhold et al., 2015) provide case studies of practical workplace risk assessment tools for SMEs (in Estonia) and an evaluation of an injury prevention intervention for metalworking micro-enterprises in Italy. Both of these studies describe practical check-list type of intervention tools that are used to provide SMEs feedback on their traditional (largely physical rather than psychosocial) workplace environments. Reinhold et al. (2015) report that the Estonian SMEs found this useful. Farina et al. (2015) describe a multi-component intervention that fits with some of the characteristics of successful interventions described in the summary of current knowledge. These included: baseline assessment visits by technicians; free training sessions for company owners, and; post-intervention inspection. Indices relating to the machinery in the SMEs and the environment were calculated and pre-post intervention differences were measured. There was a significant overall average improvement of more than $20 \%$ in the environment index but no significant improvement for the machinery. However, the proportion of machinery complying with legislation increased, but only for some specific types of machines. These findings illustrate the need for a multi-level approach to managing safety in SMEs.

\section{Additional sources of information}

As indicated earlier, using the Science Direct database for 200414 , only twenty-five papers were found to address issues specific to safety and SMEs prior to publication of this special issue. These 
papers are included in the reference list of the present paper, and are as follows: (Boustras, 2013; Cagno et al., 2013, 2011; Cheng et al., 2010; Fabiano et al., 2004; Fera and Macchiaroli, 2010; Floyde et al., 2013; Gardeux and Marsot, 2014; Hasle et al., 2010, 2009; Jørgensen et al., 2010; Kongtip et al., 2008; Makin and Winder, 2008; Masi et al., 2014; Micheli and Cagno, 2010; Morgaine et al., 2006; Moriyama and Ohtani, 2009; Pérez-Alonso et al., 2011; Santos et al., 2013; Sinclair and Cunningham, 2014; Sørensen et al., 2007; Walker and Tait, 2004).

The reader can further expand their current knowledge of this topic beyond the content of this special issue by examining five other current and recent rich sources of additional information. The first of these is the proceedings of the first USE conference, held in Elsinor, Denmark in 2009 (USE2009) (www.useconference.com). This contains a panoply of conference abstracts and papers on the original conference theme: USE - a healthy working life in a healthy business - from understanding to practice. The second and third sources are journal special issues, each resulting from the USE2009 conference (Policy and Practice in Health and Safety, Volume 08, Issue 2, 2010; International Journal of Workplace Health Management, Volume 4, Issue 2, 2011). As already mentioned in the introduction, the fourth source of additional information is the proceedings of the USE2013 conference (www.useconference.com). The fifth, and most recent, source is a special issue of the International Journal of Small Enterprise Research 'Understanding small enterprises: healthy lives in healthy businesses' (Legg et al., 2014a). It contains nine papers based on presentations at the USE2013 conference plus an editorial by the present editors (Creating healthy work in small enterprises from understanding to action: summary of current knowledge (Legg et al., 2014b), but their focus differs from that of the present special issue. For the future, the next USE conference (USE2015) is in Groningen, The Netherlands in October 2015. It also has the theme: a healthy working life in a healthy business, but with a sub-theme: Globalisation of SMEs and Corporate Social Responsibility (www.useconference.com).

\section{References}

Baldock, R., James, P., Smallbone, D., Vickers, I., 2006. Influences on small-firm compliance-related behaviour: the case of workplace health and safety. Environ. Plann. C - Government Policy 24, 827-846.

Bluff, E., Gunningham,, N., Johnstone, R., 2004. OHS Regulation for a Changing World of Work, first ed. The Federation Press, Sydney.

Boustras, G., 2013. Safety Science Special Issue with selected papers from the 1st international conference in safety and crisis management in the construction, tourism and SME sectors (1st CoSaCM). Saf. Sci. 52, 1-2.

Cagno, E., Micheli, G.J.L., Masi, D., Jacinto, C., 2013. Economic evaluation of OSH and its way to SMEs: a constructive review. Saf. Sci. 53, 134-152.

Cagno, E., Micheli, G.J.L., Perotti, S., 2011. Identification of OHS-related factors and interactions among those and OHS performance in SMEs. Saf. Sci. 49, 216-225.

Cheng, C.-W., Leu, S.-S., Lin, C.-C., Fan, C., 2010. Characteristic analysis of occupational accidents at small construction enterprises. Saf. Sci. 48, 698-707.

Clifton, R., 2000. The consequences of new enterprise structures. Mag. Eur. Agency Saf. Health Work 2, 14-18.

Cunningham, T.R., Sinclair, R., 2015. Application of a model for delivering occupational safety and health to smaller businesses: case studies from the US. Saf. Sci. 71, 213-225.

Cunningham, T.R., Sinclair, R., Schulte, P., 2014. Better understanding the small business construct to advance research on delivering workplace health and safety. Int. J. Small Enterprise Res. 21 (2), 148-160.

Dawson, S., Willman, P., Clinton, A., Bamford, M., 1988. Safety and Work: The Limits of Self-regulation. Cambridge University Press, Cambridge.

Eakin, J., Lamm, F., Limborg, H.J., Frick, K., Jensen, P.L., Quinlan, M., Wilthagen, T., 2000. International perspective on the promotion of health and safety in small workplace, systematic occupational health and safety - perspectives on an international development. Pergamon, 227-247.

Farina, F., Bena, A., Dotti, A., 2015. Impact on safety of a preventive intervention in metalworking micro-enterprises. Saf. Sci. 71, 292-297.

Fabiano, B., Currò, F., Pastorino, R., 2004. A study of the relationship between occupational injuries and firm size and type in the Italian industry. Saf. Sci. 42, 587-600.

Fera, M., Macchiaroli, R., 2010. Appraisal of a new risk assessment model for SME. Saf. Sci. 48, 1361-1368.
Floyde, A., Lawson, G., Shalloe, S., Eastgate, R., D'Cruz, M., 2013. The design and implementation of knowledge management systems and e-learning for improved occupational health and safety in small to medium sized enterprises. Saf. Sci. 60, 69-76.

Gardeux, F., Marsot, J., 2014. A 3-D interactive software tool to help VSEs/SMEs integrate risk prevention in workplace design projects. Saf. Sci. 62, 214-220.

Hasle, P., Bager, B., Granerud, L., 2010. Small enterprises - accountants as occupational health and safety intermediaries. Saf. Sci. 48, 404-409.

Hasle, P., Kines, P., Andersen, L.P., 2009. Small enterprise owners' accident causation attribution and prevention. Saf. Sci. 47, 9-19.

Hasle, P., Kvorning, L.V., Rasmussen, C.D.N., Smith, L.H., Flyvholm, M.-A., 2012a. A model for design of tailored working environment intervention programmes for small enterprises. Saf. Health Work 3, 181-191.

Hasle, P., Limborg, H.J., 2006. A review of the literature on preventive occupational health and safety activities in small enterprises. Ind. Health 44, 6-12.

Hasle, P., Limborg, H.J., Kallehave, T., Klitgaard, C., Andersen, T.R., 2012b. The working environment in small firms: responses from owner-managers. Int. Small Business J. 30, 622-639.

Holizki, T., McDonald, R., Gagnon, F., 2015. Patterns of underlying causes of workrelated traumatic fatalities - comparison between small and larger companies in British Columbia. Saf. Sci. 71, 197-204.

Holte, K.A., Kjestveit, K., Lipscomb, H.J., 2015. Company size and differences in injury prevalence among apprentices in building and construction in Norway. Saf. Sci. 71, 205-212.

Ipsen, C., Gish, L., Poulsen, S., 2015. Organizational-level interventions in small and medium-sized enterprises: enabling and inhibiting factors in the PoWRS program. Saf. Sci. 71, 264-274.

Jørgensen, K., Duijm, N.J., Troen, H., 2010. Accident prevention in SME using ORM. Saf. Sci. 48, 1036-1043.

Kongtip, P., Yoosook, W., Chantanakul, S., 2008. Occupational health and safety management in small and medium-sized enterprises: an overview of the situation in Thailand. Saf. Sci. 46, 1356-1368.

Kvorning, L.V., Hasle, P., Christensen, U., 2015. Motivational factors influencing small construction and auto repair enterprises to participate in occupational health and safety programmes. Saf. Sci. 71, 253-263.

Laird, I., Olsen, K., Harris, L.-A., Legg, S., 2011. Utilising the characteristics of small enterprises to assist in managing hazardous substances in the workplace. Int. J. Workplace Health Manage. 4, 140-163.

Lamm, F., 1999. Occupational health and safety in Australian small business: what can be done to reduce the lack of awareness and raise the level of compliance in Australian small business? Sydney Industrial Relations Research Centre, The University of New South Wales.

Legg, S., Battista, M., Harris, L.-A., Laird, I., Lamm, F., Massey, C., Olsen, K., 2009. Occupational Health and Safety in Small Businesses. National Occupational Health and Safety Committee, Wellington.

Legg, S., Laird, I., Olsen, K.B., Hasle, P., 2014a. Understanding small enterprises: healthy lives in healthy businesses. Int. J. Small Enterprise Res. (Special Issue) 21 (2), 138-237.

Legg, S., Laird, I., Olsen, K.B., Hasle, P., 2014b. Guest Editorial: Creating healthy work in small enterprises - from understanding to action: summary of current knowledge. Int. J. Small Enterprise Res. (Special Issue) 21 (2), 139-147.

Makin, A.M., Winder, C., 2008. A new conceptual framework to improve the application of occupational health and safety management systems. Saf. Sci. 46, 935-948.

Masi, D., Cagno, E., 2015. Barriers to OHS interventions in small and medium-sized enterprises. Saf. Sci. 71, 226-241.

Masi, D., Cagno, E., Micheli, G.J.L., 2014. Developing, implementing and evaluating OSH interventions in SMEs: a pilot, exploratory study. Int. J. Occupational Saf. Ergonomics 20, 385-405.

Mayhew, C., Peterson, C., 1999. Why Owner/Managers in Small Business Miss Out, Occupational Health and Safety in Australia.

Mayhew, C., Quinlan, M., 1999. The effects of outsourcing on occupational health and safety: a comparative study of factory-based workers and outworkers in the Australian clothing industry. Int. J. Health Services 29, 83-107.

Micheli, G.J.L., Cagno, E., 2010. Dealing with SMEs as a whole in OHS issues: warnings from empirical evidence. Saf. Sci. 48, 729-733.

Morgaine, K., Langley, J.D., McGee, R.O., 2006. The FarmSafe Programme in New Zealand: process evaluation of year one (2003). Saf. Sci. 44, 359-371.

Moriyama, T., Ohtani, H., 2009. Risk assessment tools incorporating human error probabilities in the Japanese small-sized establishment. Saf. Sci. 47, 1379-1397.

Morse, T., Dillon, C., Weber, J., Warren, N., Bruneau, H., Fu, R., 2004. Prevalence and reporting of occupational illness by company size: population trends and regulatory implications. Am. J. Ind. Med. 45, 361-370.

Okun, A., Lentz, T.J., Sieber, W.K., Jones, J.H., Piacitelli, G.M., Catlett, L.R., Schulte, P.A., Stayner, L., 2001. Identifying high-risk small business industries for occupational safety and health interventions. Am. J. Ind. Med. 39, 310-311.

Olsen, K., Harris, L.-A., Laird, I., Legg, S., Perry, M., Hasle, P., 2010. Differential intervention strategies to improve the management of hazardous chemicals in small enterprises. Policy Practice Health Saf. 8, 57-76.

Olsen, K., Legg, S., Hasle, P., 2012. How to use programme theory to evaluate the effectiveness of schemes designed to improve the work environment in small businesses. WORK: J. Prevention Assess. Rehabilitation 41, 5999-6006.

Olsen, K.B., Hasle, P., 2015. The role of intermediaries in delivering an occupational health and safety programme designed for small businesses a case study of an insurance incentive programme in the agriculture sector. Saf. Sci. 71, 242-252. 
Ozmec, M.N., Karlsen, I.L., Kines, P., Andersen, L.P.S., Nielsen, K.J., 2015. Negotiating safety practice in small construction companies. Saf. Sci. 71, 275-281.

Pérez-Alonso, J., Carreño-Ortega, Á., Callejón-Ferre, Á.J., Vázquez-Cabrera, F.J., 2011. Preventive activity in the greenhouse-construction industry of south-eastern Spain. Saf. Sci. 49, 345-354.

Quinlan, M., 1999. The implications of labour market restructuring in industrialized societies for occupational health and safety. Econ. Ind. Democracy 20, 427-460.

Quinlan, M., Bohle, P., Lamm, F., 2010. Managing Occupational Health and Safety; A Multidisciplinary Approach, third ed. Palgrave Macmillan.

Reinhold, K., Järvis, M., Tint, P., 2015. Practical tool and procedure for workplace risk assessment: evidence from SMEs in Estonia. Saf. Sci. 71, 282-291.

Robens, 1972. Safety and Health at Work: Report of the Committee 1970-72. HMSO, London.

Santos, G., Barros, S., Mendes, F., Lopes, N., 2013. The main benefits associated with health and safety management systems certification in Portuguese small and medium enterprises post quality management system certification. Saf. Sci. 51 29-36.

Sinclair, R.C., Cunningham, T.R., 2014. Safety activities in small businesses. Saf. Sci. $64,32-38$

Sinclair, R.C., Cunningham, T.R., Schulte, P.A., 2013. A model for occupational safety and health intervention diffusion to small businesses. Am. J. Ind. Med. 56, 1442-1451.
Sørensen, O.H., Hasle, P., Bach, E., 2007. Working in small enterprises - is there a special risk? Saf. Sci. 45, 1044-1059.

Stevens, G., 1999. Features - workplace injuries in small and large manufacturing workplaces - an analysis of the risks of fatal and non-fatal injuries, including figures for 1994/5-1995/6. Labour Market Trends 107, 19-26.

Storey, D.J., 1994. Understanding the Small Business Sector. Routledge, London.

Targoutzidis, A., Koukoulaki, T., Schmitz-Felten, E., Kuhl, K., Hengel, K.M.O. Rijken, E., Van den Broek, K., Klüser, R., 2014. The business case for safety and health at work: cost-benefit analyses of interventions in small and medium-sized enterprises. European Agency for Safety and Health at Work, Luxembourg.

Walker, D., Tait, R., 2004. Health and safety management in small enterprises: an effective low cost approach. Saf. Sci. 42, 69-83.

Walters, D., 2001. Health and Safety in Small Enterprises: European Strategies for Managing Improvement. P.I.E.-Peter Lang, Brussels.

Walters, D., 2006. The efficacy of strategies for chemical risk management in small enterprises in Europe: evidence for success? Policy Practice Health Saf. 4, 81 116.

Walters, D., Johnstone, R., Frick, K., Quinlan, M., Baril-Gingas, G., Thébaud-Mony, A 2011. Regulating workplace risks: a comparative study of inspector regimes in times of change, first ed. Edward Elgar Publishing Inc., Cheltenham, UK. 